\title{
A retrospective study of gynecomastia in male patients referred to Hatyai Hospital with breast lesions
}

\author{
Manas Kotepui ${ }^{\mathrm{a}}$, Duangjai Piwkham ${ }^{\mathrm{a}}$, Chaowanee Chupeerach ${ }^{\mathrm{b}}$, Apiram Songsric \\ ${ }^{a}$ Medical Technology Program, School of Allied Health Sciences and Public Health, Walailak University, \\ Nakhon Si Thammarat 80161, 'Institute of Nutrition, Mahidol University, Nakhon Pathom 73170, \\ 'Department of Pathology, Hatyai Hospital, Songkhla 90110, Thailand
}

\begin{abstract}
Background: Gynecomastia is a common benign lesion of the male breast and accounts for up to $80 \%$ of male patients referred with beast lesions.

Objective: To examine the pattern of breast lesions in male patients who underwent breast biopsy.

Methods: All male patients referred to Hatyai Hospital with breast complaints were included in the study. Histopathology reports were retrospectively reviewed during 2004-2011.

Results: In 77 male patients diagnosed with breast lesions, the most common lesion was gynecomastia (49/77, $64 \%)$, followed by fibrocystic changes (7/77, 9\%), and breast cancer (6/77, 8\%). Gynecomastia was commonly found in male patients less than 40 years of age, while other breast lesions are seen in male patients over 40 years of age $(P=0.036$, OR $=2.842,95 \% \mathrm{CI}=1.085-7.447)$.

Conclusion: Gynecomastia was the most common diagnosis among breast lesions in male patients referred to the Hatyai Hospital during 2004-2011. Gynecomastia was more common in the patients less than 20 years old.
\end{abstract}

Keywords: Gynecomastia, male breast lesions, Thailand

Gynecomastia is a benign enlargement of the male breast because of proliferation of its glandular components. It is common in mild transient form in $30 \%-50 \%$ of healthy male patients [1]. Causes of gynecomastia are largely idiopathic. Identified causes of gynecomastia are hypogonadism (25\%), hyperprolactinemia (9\%), chronic liver disease (4\%), and drug induced (4\%) [2]. Gynecomastia is thought to result from several mechanisms including increased androgen and leptin levels, human chorionic gonadotropin, and luteinizing hormone $[3,4]$. The majority of male patients with gynecomastia are asymptomatic and referred for persistently tender breasts, palpable lump, or disturbed body image [5]. Previous studies reported that new cases of gynecomastia accounted for up to $80 \%$ of male patients referred to hospitals with breast lesions [6-11]. The aim of this study was to examine the nature of male breast lesions, especially those diagnosed as gynecomastia at Hatyai Hospital over the past 8 years (2004-2011).

Correspondence to: Manas Kotepui, Medical Technology Program, School of Allied Health Sciences and Public Health, Walailak University, Nakhon Si Thammarat 80161, Thailand. E-mail: manas.ko@wu.ac.th

\section{Materials and methods}

The study was approved by the Ethics Committee of Hatyai Hospital. This retrospective study analyzed histopathology reports of men who were referred to Hatyai Hospital, Songkhla, Thailand during 2004-2011. All data were verified, checked for duplication and coded. The clinical details of patients included age at diagnosis and histopathology diagnosis. Excel and SPSS version 11.5 (SPSS Inc, Chicago, IL, USA) was used. $P<0.05$ were considered significant.

\section{Results}

There were 77 men referred to Hatyai Hospital with an age range of 4-86 years (median 40) during 2004-2011. The most frequent breast lesion diagnosed was gynecomastia $(49 / 77,64 \%)$, followed by fibrocystic changes $(7 / 77,9 \%)$, cancer $(6 / 77,8 \%)$, fibroadenoma (4/77, 5\%), lipoma (3/77, 4\%), and others (Table 1). In the rst year, there were 5 men referred to the Hospital. By 2011, this number had increased to 26 (Figure 1). The prevalence of gynecomastia in different age groups is shown in Figure 2. Gynecomastia was more common in male patients less than 20 years of age $(7 / 8,88 \%)$, followed by $20-39$ years of age (21/30, $70 \%)$, over 60 years of 
age (9/14, $64 \%)$, and $40-59$ years of age $(12 / 25,48 \%)$. This indicates that gynecomastia occurs more commonly in male patients under 40 years of age; while other breast lesions occurred in patients aged 40 years or older $(P=0.036, \mathrm{OR}=2.842,95 \% \mathrm{CI}=$ 1.085-7.447) (Table 2). The overall proportion of breast cancer was $8 \%$ (6/77). Breast cancer occurred in about one third ( $2 / 6$ of each age group) of 20-39year-old patients, 40-60 year-old patients, and over 60 year-old patients. Invasive ductal carcinoma was the most common type diagnosed (3/6) as shown in Table 3.

Table 1. Breast lesions in men with age distribution

\begin{tabular}{llllll}
\hline Breast disease/male & \multicolumn{3}{c}{ Age group in years, n (\%) } & \multirow{2}{*}{ Total } \\
\cline { 2 - 4 } & $<\mathbf{2 0}$ & $\mathbf{2 0 - 3 9}$ & $\mathbf{4 0 - 5 9}$ & $\mathbf{2 6 0}$ & \\
\hline Gynecomastia & $7(88 \%)$ & $21(70 \%)$ & $12(48 \%)$ & $9(64 \%)$ & $49(64 \%)$ \\
Fibrocystic change & 0 & $2(7 \%)$ & $3(12 \%)$ & $2(14 \%)$ & $7(9 \%)$ \\
Breast cancer & 0 & $2(7 \%)$ & $2(8 \%)$ & $2(14 \%)$ & $6(8 \%)$ \\
Fibroadenoma & 0 & $3(10 \%)$ & $1(4 \%)$ & 0 & $4(5 \%)$ \\
Lipoma & 0 & 0 & $2(8 \%)$ & $1(7 \%)$ & $3(4 \%)$ \\
Inflammation & 0 & $1(3 \%)$ & $1(4 \%)$ & 0 & $2(3 \%)$ \\
Arteriovenous malformation & 0 & $1(3 \%)$ & 0 & 0 & $1(1 \%)$ \\
Axillary breast & 0 & 0 & $1(4 \%)$ & 0 & $1(1 \%)$ \\
Duct ectasia & 0 & 0 & $1(4 \%)$ & 0 & $1(1 \%)$ \\
Dystrophic calcification & $1(13 \%)$ & 0 & 0 & 0 & $1(1 \%)$ \\
Epidermal inclusion cyst & 0 & 0 & $1(4 \%)$ & 0 & $1(1 \%)$ \\
Fibrolipoma & 0 & 0 & $1(4 \%)$ & 0 & $1(1 \%)$ \\
\hline Total & $8(100 \%)$ & $30(100 \%)$ & $25(100 \%)$ & $14(100 \%)$ & $77(100 \%)$ \\
\end{tabular}

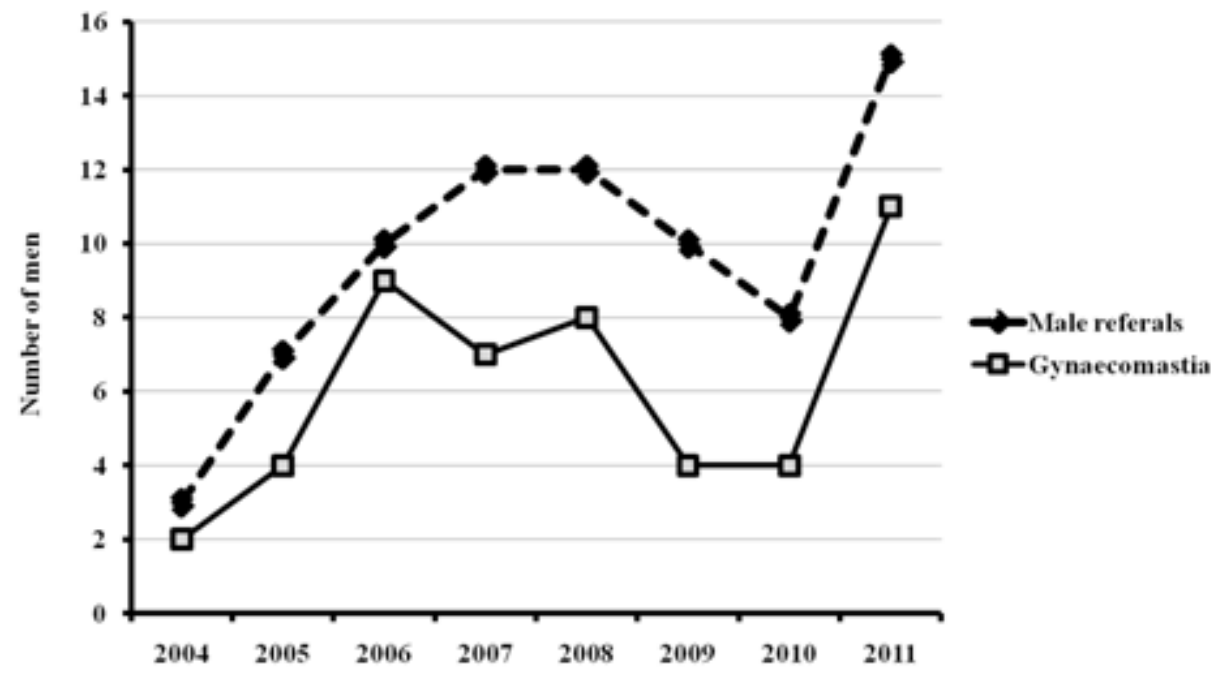

Figure 1. Trend in incidence of breast lesion in men during 2004-2011 


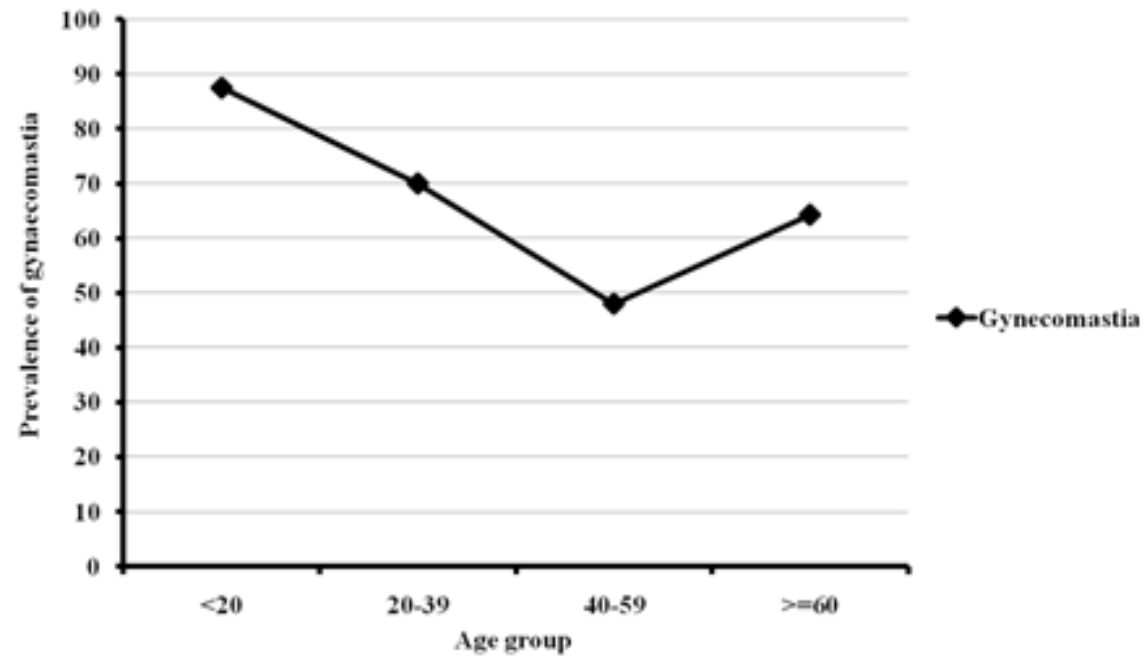

Figure 2. Prevalence of gynecomastia in different age groups

Table 2. Prevalence of gynecomastia and other breast lesions

\begin{tabular}{|c|c|c|c|c|c|}
\hline \multirow[b]{2}{*}{ Age groups } & \multicolumn{2}{|c|}{ Breast lesions } & \multirow[b]{2}{*}{ Total } & \multirow[b]{2}{*}{$\boldsymbol{P}$} & \multirow[b]{2}{*}{ OR (95\%CI) } \\
\hline & Gynomastia & Other diseases & & & \\
\hline 40 & $30(61 \%)$ & $10(36 \%)$ & $40(52 \%)$ & 0.036 & $2.842(1.085-7.447)$ \\
\hline$>40$ & $19(39 \%)$ & $18(64 \%)$ & $37(48 \%)$ & & \\
\hline Total & $49(100 \%)$ & 28(100\%) & $77(100 \%)$ & & \\
\hline
\end{tabular}

$P$ by Fisher's Exact Test

Table 3. Breast cancer types in men

\begin{tabular}{lcccc}
\hline \multirow{2}{*}{ Breast cancer type } & \multicolumn{3}{c}{ Age group in years, $\mathbf{n}(\mathbf{\%})$} & \multirow{2}{*}{ Total } \\
\cline { 2 - 3 } & $\mathbf{2 0 - 3 9}$ & $\mathbf{4 0 - 5 9}$ & $\mathbf{2 6 0}$ & \\
\hline Ductal carcinoma & 1 & 2 & 0 & 3 \\
Lobular carcinoma & 1 & 0 & 0 & 1 \\
Malignant lymphoma (B-cell type) & 0 & 0 & 1 & 1 \\
Squamous cell carcinoma & 0 & 0 & 1 & 1 \\
\hline Total & 2 & 2 & 2 & 6 \\
\hline
\end{tabular}

\section{Discussion}

There were an increasing number of male patients referred to Hatyai Hospital with breast lesions and an increased number of male patients diagnosed with gynecomastia during 2004-2011. In the first year (2004), there were 5 men referred to the Hatyai Hospital; by 2011 the number had risen to 26 per year. This study indicates that gynecomastia was the most common breast lesion in male patients in the south of Thailand, while other breast lesions were related to cutaneous and subcutaneous tissues (fibrocystic change, breast cancer, fibroadenoma, lipoma, and arteriovenous malformation). The overall prevalence of gynecomastia in male patients referred to Hatyai Hospital with breast lesions during 8 years was $64 \%$. This is higher than in Austria (51.2\%) [12], Nepal (60\%) [13], and Nigeria (61.9\%) [14]. It was lower than that in Italy (66.07\%) [15], USA (67.3\%) [16], UK (74.4\%) [5], Spain (80.4\%) [7], South Africa (82.7\%) [8], and India (84.3\%) [9]. A high prevalence of gynecomastia was also reported from Turkey (100\%) [10], and Pakistan (100\%) [11]. Male patients with gynecomastia often become anxious and seek medical attention. Although gynecomastia is a benign condition that may not require speci c treatment, it can have a psycho-social impact on self-image [17] 
and even result in inappropriate mastectomies [18]. Gynecomastia appeared to be more pronounced in patients less than 20 years of age. This was similar to findings in a previous study [5]. However, one study reported that more severe gynecomastia was seen in patients from 20 to 24 years old and in those over 44 years old (57\%), compared with those 19 years old or younger [19]. This differs from findings in our study. Generally, there are three distinct peaks in age distribution of gynecomastia: the neonatal period because of maternal hormones, during puberty (peaking at 13-14 years old); and in an adult population (the highest prevalence was at 50-80 years old) [20]. Gynecomastia, related to an increase in the ratio of estrogen to androgen during the neonatal period and puberty [21]. Gynecomastia in later adulthood usually reflects aging related physiologic changes involving declining androgen and free testosterone levels, accumulation of adipose tissue and increasing aromatase activity (obesity) [21, 22]. This could explain the prevalence of gynecomastia in our study, which was more common in patients less than 20 years old, less common in those from 40 to 59 years old, and increased in those older than 60 years. Male breast cancer, which is a rare disease [23, 24], was found in patients of a wide range of ages among this relative small study population. The main limitation of this study is that our patients may not be an entirely true representation of the general male population. Alarger study in this population to confirm our findings is warranted.

\section{Conclusions}

Gynecomastia is the most common diagnosis in male patients referred to Hatyai Hospital with breast complaints during 2004-2011. It involved mostly male patients less than 20 years of age. Patients with gynecomastia often become anxious and seek medical attention and mostly require reassurance.

\section{Acknowledgements}

The authors would like thank Dr. Lek Charoenkijkajorn, Head of the Department of Pathology, Hatyai Hospital, Songkhla, Thailand for his support, assistance and giving us opportunity to do this project. The authors declare that they have no conflicts of interest.

\section{References}

1. Gikas P, Mokbel K. Management of gynaecomastia: an update. Int J Clin Pract. 2007; 61:1209-15.

2. Ersoz H, Onde ME, Terekeci H, Kurtoglu S, Tor H. Causes of gynaecomastia in young adult males and factors associated with idiopathic gynaecomastia. Int JAndrol. 2002; 25:312-6.

3. Nordt CA, DiVasta AD. Gynecomastia in adolescents. Curr Opin Pediatr. 2008; 20:75-382.

4. Braunstein GD. Gynecomastia. N Engl J Med. 2007; 357:1229-37.

5. Al-Allak A, Govindarajulu S, Shere M, Ibrahim N, Sahu AK, Cawthorn SJ. Gynaecomastia: a decade of experience. Surgeon. 2011; 9:255-8.

6. Hanavadi S, Banerjee D, Monypenny IJ, Mansel RE. The role of tamoxifen in the management of gynaecomastia. Breast. 2006; 15:276-80.

7. Munoz Carrasco R, Alvarez Benito M, Munoz Gomariz E, Raya Povedano JL, Martinez Paredes M. Mammography and ultrasound in the evaluation of male breast disease. Eur Radiol. 2010; 20:2797-805.

8. Michelow P, Dezube BJ, Pantanowitz L. Fine needle aspiration of breast masses in HIV-infected patients: results from a large series. Cancer Cytopathol. 2010; 118:218-24.

9. Singh R, Anshu, Sharma SM, Gangane N. Spectrum of male breast lesions diagnosed by fine needle aspiration cytology: a 5-year experience at a tertiary care rural hospital in central India. Diagn Cytopathol. 2012; 40:113-7.

10. Sonmez K, Turkyilmaz Z, Karabulut R, Demirogullari B, Ozen IO, Moralioglu S, et al. Surgical breast lesions in adolescent patients and a review of the literature. Acta Chir Belg. 2006; 106:400-4.

11. Aslam HM, Saleem S, Shaikh HA, Shahid N, Mughal A, Umah R. Clinico- pathological profile of patients with breast diseases. Diagn Pathol. 2013; 8:77.

12. Partik B, Mallek R, Rudas M, Pokieser P, Wunderbaldinger P, Helbich TH. [Malignant and benign diseases of the breast in 41 male patients: mammography, sonography and pathohistological correlations]. Rofo. 2001; 173:1012-8. (in German)

13. Kumar R. A clinicopathologic study of breast lumps in Bhairahwa, Nepal. Asian Pac J Cancer Prev. 2010; 11:855-8.

14. Olu-Eddo AN, Ugiagbe EE. Benign breast lesions in an African population: a 25-year histopathological review of 1864 cases. Niger Med J. 2011; 52:211-6.

15. Ambrogetti D, Ciatto S, Catarzi S, Muraca MG. The combined diagnosis of male breast lesions: a review of a series of 748 consecutive cases. Radiol Med. 1996; 91:356-9. 
16. Evans GF, Anthony T, Turnage RH, Schumpert TD, Levy KR, Amirkhan RH, et al. The diagnostic accuracy of mammography in the evaluation of male breast disease. Am J Surg. 2001; 181:96-100.

17. Nuzzi LC, Cerrato FE, Erikson CR, Webb ML, Rosen H, Walsh EM, et al. Psychosocial impact of adolescent gynecomastia: a prospective case-control study. Plast Reconstr Surg. 2013; 131:890-6.

18. Charlot M, Beatrix O, Chateau F, Dubuisson J, Golfier F, Valette PJ, et al. Pathologies of the male breast. Diagn Interv Imaging. 2013; 94:26-37.

19. Nuttall FQ. Gynecomastia as a physical finding in normal men. J Clin Endocrinol Metab. 1979; 48:338-40.
20. Braunstein GD. Gynecomastia. N Engl J Med. 1993; 328:490-5.

21. Karnath BM. Gynecomastia. Hospital Physician. 2008; 44:45-51.

22. Niewoehner CB, Nuttal FQ. Gynecomastia in a hospitalized male population. Am J Med. 1984; 77: 633-8.

23. Gomez-Raposo C, Zambrana Tevar F, Sereno Moyano M, Lopez Gomez M, Casado E. Male breast cancer. Cancer Treat Rev. 2010; 36:451-7.

24. Tallon-Aguilar L, Serrano-Borrero I, Lopez-Porras M, Sousa-Vaquero JM, de Leon-Carrillo J. Breast cancer in males. Cir Cir. 2011; 79:296-8. 